\title{
The optimal management of variant histology in muscle invasive bladder cancer
}

\author{
Raj Vikesh Tiwari ${ }^{1}$, Nye Thane Ngo $^{2}$, Lui Shiong Lee ${ }^{2}$ \\ ${ }^{1}$ Department of Urology, Sengkang General Hospital, Singapore; ${ }^{2}$ Department of Anatomical Pathology, Singapore General Hospital, Singapore \\ Contributions: (I) Conception and design: RV Tiwari, LS Lee; (I) Administrative support: None; (I) Provision of study material or patients: NT Ngo; (I) \\ Collection and assembly of data: VT Raj, LS Lee; (I) Data analysis and interpretation: VT Raj, LS Lee; (I) Manuscript writing: All authors; (I) Final \\ approval of manuscript: All authors. \\ Correspondence to: Lui Shiong Lee. Department of Urology, Sengkang General Hospital, 110 Sengkang East Way, Singapore 544886, Singapore. \\ Email: Lee.lui.shiong@singhealth.com.sg.
}

\begin{abstract}
Bladder cancer is a heterogenous disease that is associated with tangible mortality in muscle invasive disease. The WHO 2016 classification of urothelial tumours reflects the contemporary approach towards histological variants in bladder cancer, including variants of urothelial carcinoma (UC) and nonurothelial variants. This review focuses on variant histology in UC, and discusses the importance of accurate histological diagnosis, and subsequent risk stratification and therapeutic decision making based on proper variant recognition. Most urothelial variants are associated with poorer outcomes compared to conventional UC, although some perform reasonably better. However, high quality evidence detailing optimal treatment and survival outcomes are still lacking in literature, due to the rarity of these cases.
\end{abstract}

Keywords: Bladder cancer; therapy; urinary bladder neoplasms

Submitted Sep 23, 2019. Accepted for publication Dec 25, 2019.

doi: $10.21037 /$ tau.2020.01.02

View this article at: http://dx.doi.org/10.21037/tau.2020.01.02

\section{Introduction}

Bladder cancer is currently one of the top ten most common solid organ malignancies worldwide, and comprising approximately 550,000 new cases and 200,000 deaths in $2018(1,2)$. Bladder cancer is a heterogenous disease with superficial non-invasive disease being more common and associated with good outcomes while aggressive muscle invasive disease is associated with poorer prognosis (3). In patients with muscle invasive disease, a wide array of treatment modalities have been described inclusive of systemic chemotherapy and immunotherapy, radical cystectomy (RC) and bladder sparing regimes including maximal transurethral resection combined with radiotherapy with chemotherapy (4).

In pure bladder cancer variants, the diagnosis and treatment are largely distinct from conventional urothelial carcinoma (UC) of the bladder (5). However, the optimal management of urothelial cancer variants in muscle invasive disease may have considerable overlap with that of their conventional counterpart. Hence, there is strong clinical relevance to urologists, pathologists and oncologists alike to be able to distinguish between these variants confidently, especially in subtypes where the treatment and prognosis may be different from conventional UC.

This article focuses on the key features of histological variants of conventional UC especially in the context of muscle invasive bladder cancer (MIBC), and explores the available evidence of prognostication and treatment of individual variants.

\section{Evidence acquisition}

A non-systematic PubMed and Medline literature search was performed using the following terms alone or in combination: "bladder cancer", "urothelial cancer", "micropapillary", "microcystic", "sarcomatoid variant", nested variant", " plasmacytoid variant", "clear cell”, "giant 
Table 1 Differences in nomenclature of histologic variants in muscle invasive disease between 2002 and 2016 WHO classification

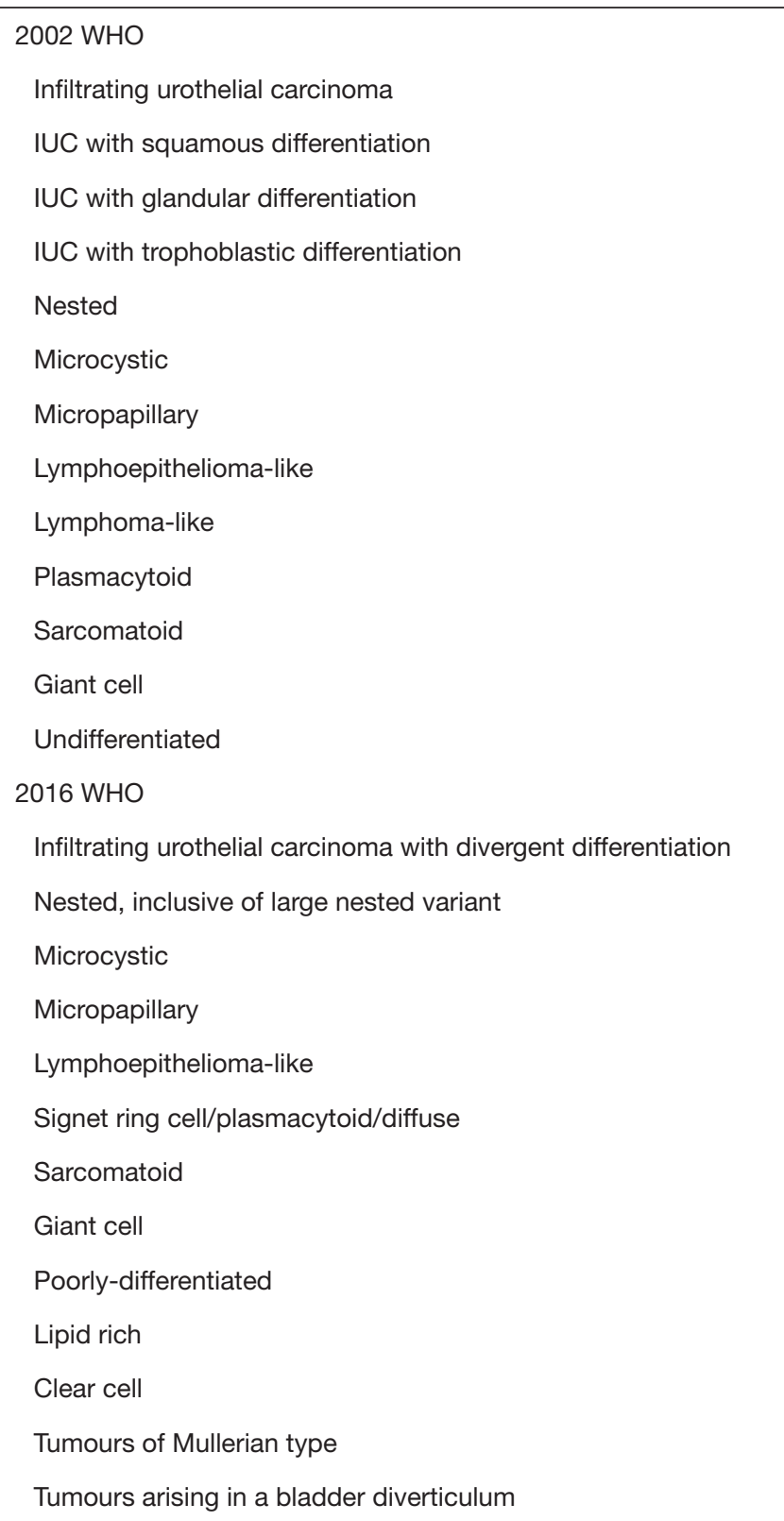

IUC, infiltrating urothelial carcinoma.

cell", "histological variants" and "muscle invasive bladder cancer". Meta-analysis, original articles and reviews in published in English were chosen.

\section{Case definition}

In 2016, WHO released the fourth edition of the classification of tumours of the urothelial tract, and detailed a section on histological variants in recognition of divergent differentiation, morphology and clinical phenotype (6) (Table 1). The updates reflected recognition of variant tumour histology as distinct in diagnosis, pathogenesis and ultimately, in the realm of clinical trials and therapeutics. On the other hand, the grading classification is retained, and WHO 2016 recommendations are largely based on the WHO 2004 (7) grading of low grade and high grade tumours.

By definition, these tumours have primarily $\mathrm{UC}$ as the predominant histological subtype, but other subtypes are also observed. The incidence of divergent differentiation or histologic variants is estimated to be about $25 \%$ in cystectomy series $(8,9)$, and are therefore, not uncommon in incidence.

Given the lack of tumour markers in bladder cancer, accurate pathological grading and histological subtype is critical to optimal clinic decision-making on treatment and appropriate patient counselling. However, histological variants may not be consistently reported or recognised. There may be a high discordance rate between pathological reporting of specimens obtained from transurethral resection and cystectomy numbering between 39-47\%, often due to a lack of recognition by community pathologists (10). In the specific example of micropapillary variant of $\mathrm{UC}$, consistent pathological reporting is challenged by significant interobserver variation even among urologic pathologists (11), and a lack of specific and sensitive immunohistochemical markers $(12,13)$.

Of the available studies in English literature, most of them suggest that variant histology in bladder cancer, whether muscle invasive or not, will portend a poorer clinical outcome of survival in affected patients, when compared to conventional UC. Generally, there is a higher propensity for extra-vesical extension and lymph node metastasis (14), and also a tendency for pathological upstaging at $\mathrm{RC}$ (hazard ratio of 2.77) compared to conventional UC (15). However, the strength of evidence for prognosis and optimal treatment varies between tumour variants depending on the quality of available evidence. Hence, specific recommendations will be detailed in the relevant sections that follow.

\section{Urothelial malignancies and variant types}

\section{Micropapillary urothelial carcinoma (MPUC)}

MPUC was first described in the early 1990s at MD 


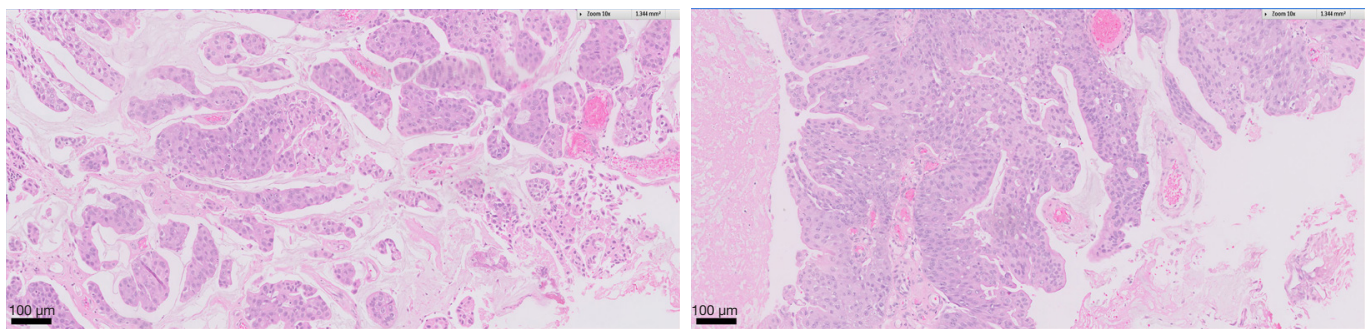

Figure 1 Micropapillary bladder cancer. (A) H\&E slide showing invasive component of tumour; (B) H\&E slide showing mucosal component of tumour.

Anderson Cancer Centre by Amin et al. (16) as a tumour growth pattern that occurs in many organs usually presenting at an advanced stage.

The microscopic features of MPUC include a micropapillary architecture similar to that of ovarian papillary serous tumours, and this can be observed to be at the mucosal surface or in the invasive component of the tumour. The nuclei of tumour cells are frequently of high grade, showing reversed polarity to the external surface of tumour nests (17) (Figure 1).

The proportion of MPUC in the tumour is prognostic for clinical outcomes, and should be routinely reported if present (18).

The incidence of MPUC is estimated to be between $0.7 \%$ to $2.2 \%$ of all urothelial tumours, with a male to female ratio of 10:1 and average age of diagnosis of 65 years. A majority of patients were found with muscle invasive disease at presentation, and the overall survival (OS) outcomes at 5 and 10 years were $51 \%$ and $24 \%$ respectively (19). In earlier surgical series, there was also a high progression rate $(70 \%)$ from non-muscle invasive to muscle-invasive disease, and nodal metastasis despite aggressive treatment. This is associated with a high tendency for pathological upstaging in the MPUC components at cystectomy (20).

In non-muscle invasive disease, the optimal treatment with either early RC or intravesical BCG is not known (14,21-23). Kamat et al. suggested that early cystectomy was indicated in non-muscle invasive MPUC as there was a high rate of progression to MIBC with intravesical Bacillus Calmette Guerin (BCG) therapy. However, this was reported from a study with a small sample size $(\mathrm{n}=27)$ and the wider applicability is not clear (15). Spaliviero et al. showed no significant difference in cancer specific mortality or risk of metastasis between early RC and intravesical BCG, although there was a tendency for better outcomes with early RC. This study was also limited by sample size $(n=36)$.

In a more contemporary study of 82 patients with nonmetastatic MIBC, Meeks et al. demonstrated a $45 \%$ pT0 rate following neoadjuvant cisplatin based chemotherapy followed by RC, and also showed better OS in pT0 individuals than those with residual disease (24). However, despite a response to NAC in some patients, a pooled analysis showed that NAC did not confer a OS or cancer specific survival (CSS) compared to RC alone (25). However, there was an intermediate to high risk of bias across these studies observed.

It is also possible to clinically risk stratify patients with surgically resectable MPUC-namely those with clinical $\mathrm{T} 1$, clinical $\mathrm{T} 2$ or more without hydronephrosis and any clinical stage with hydronephrosis (26). The 5 -year OS rates were $82 \%, 45 \%$ and $15 \%$ respectively, while DSS rates were $92 \%, 51 \%$ and $17 \%$ respectively. They suggested upfront RC for the lower risk group (5 years OS and DSS of $87 \%$ and $95 \%$ ), and neoadjuvant chemotherapy (NAC) and RC for the high risk group (5-year OS and DSS 64\% and $79 \%$ respectively). For the highest risk group with hydronephrosis, the OS and DSS were very poor (24\% and $27 \%$ ) with upfront RC, and poorer with NAC prior to RC. However, this study was limited by a sample size of $n=107$ patients and would require validation from larger patient populations.

Whole genome sequencing of MPUC has yielded a genomic signature typical of a luminal subtype associated with the activation of wild-type p53 mutations, which would possibly explain its aggressive biological behaviour (27).

Hence, based on available clinical evidence drawn from case series, there is a suggestion to support early RC in T1 disease where suitable. Otherwise, intravesical BCG may also provide disease control in those not suitable for radical surgery but with a potentially poorer OS. In patients with MIBC, there should be consideration of NAC based on 
conventional UC regime. This should be followed by RC especially in those with good clinical response.

\section{Giant cell variant (GCV)}

The GCV of UC is a very rare entity first described by Kitazawa et al. (28). It is essentially a high grade carcinoma, which appears undifferentiated and is characterized by the presence of epithelial tumor giant cells exhibiting marked nuclear atypia, along with a component of conventional urothelial carcinoma, and is initially identified as an undifferentiated UC. Although bearing resemblance with giant cell tumors of the lung, these urothelial variants are distinct from other giant cell described within other bladder tumors, including osteoclast like giant cells occasionally seen in reactive lesions, syncytiotrophoblasts, sarcomatoid variant of UCs and giant cells of the so called giant tumor of the bladder which is indistinguishable from giant cell tumour of bone and lacks urothelial differentiation (29).

Microscopically, the giant cells variant of shows marked nuclear pleomorphism, typically with multiple nuclei, and consists of cohesive cells with abundant eosinophilic cytoplasm. Malignant giant cells when present in great numbers, portend a poor clinical prognosis $(30,31)$.

An accurate histopathological diagnosis requires IHC to differentiate GCV from the conventional UC and undifferentiated carcinoma, including the application of epithelial markers of cytokeratin and epithelial membrane antigen. Vimentin and keratin can distinguish GCV from similar mesenchymal lesions arising in the urinary bladder. Additionally GCV does not stain positively with tartrate resistant acid phosphatase which is a characteristic of osteoclastic giant cell tumours $(29,32,33)$.

Common misdiagnosis of this variant could be secondary carcinomas or sarcoma in limited samples which could lead to very different treatment approaches (34). Other differentials would include metastatic giant cell carcinomas of lung, melanoma or direct extension of prostate giant cell carcinoma. In the latter case, background conventional UC can aid in confirming the impression of a bladder primary.

Due to its rarity, there are less than twenty cases reported so far (28,29,31-33,35-37). The typical clinical presentation is that of haematuria with a significant mass in the bladder. The natural history of GCV has been variable and elucidation of longer term behaviour limited by followup durations reported on. TURBT alone provided short term control in three cases $(32,35)$, while RC was indicated in two cases $(28,36)$.
One case was reported in a renal transplant recipient 12 years post allograft implant and BK virus positive (37), which was treated with radical surgery.

Hence, from limited evidence available, it would be reasonable to pursue bladder sparing surgery with maximal TURBT in those with non-muscle invasive disease, while radical treatment should be considered in those with MIBC.

\section{Microcystic carcinomas}

Microcystic carcinoma (MC) was first described in 1991 by Robert et al., presenting 4 cases arising in the bladder. The 2004 WHO classification were the first recommendations to make a distinction between microcystic variant of UC and UC with gland-like lumina (7). To date, there are about 30 cases so far. The largest case series comprise 20 cases where all patients presented with macroscopic haematuria, and the appropriate histological variant diagnosis of $\mathrm{MC}$ was only made at $\mathrm{RC}$ in half of the patients. At microscopy, the cysts were observed to be of variable sizes up to $1.1 \mathrm{~mm}$. These cysts were lined by a single or several layers of urothelial cells, with the lining epithelium denude in some (38). There is also prominent intercellular or intracellular lumina with no true glands, and no colonic epithelium or goblet cells are observed (39). IHC expression of MC showed that most tumours expressed MUC5A, GATA3, CK7 and MUC1 (38).

There are two postulates for the etiology of MC for this rare variant, namely having cyst-like structures which emanate from urothelium forming spaces within the bladder, or arising from cellular degeneration which leads to the presence of luminal debris and necrotic cells (40).

The differential diagnosis of MC include many benign histologic patterns, including cystitis glandularis and hence, in clinical situations where only limited specimens are available, there is a high possibility of misdiagnosis $(29,38)$. The often dramatic variations in nuclear size, in addition to other atypical characteristics, is a helpful distinguishing feature of the microcystic variant of UC. The invasive nature of the lesion into lamina propria or detrusor muscle will help in differentiation from benign pathology.

Another diagnostic consideration is primary or metastatic adenocarcinoma. Although the cysts of the microcystic variant may resemble small infiltrating glans and may produce mucin, the architecture and cytology of the lining epithelium are distinctly urothelial in nature (38).

In an earlier case series, $\mathrm{Paz}$ et al. described a series of 12 cases of MC admixed with high grade UC. A majority 
of patients presented with T1 and above tumour stage (41). When compared stage for stage with conventional UC, the presence of MC variant did not adversely affect OS (38). The poor outcomes of $\mathrm{MC}$ reported in literature were likely related to the advanced stage at presentation.

Therefore, the MC variant may be mistakenly diagnosed as cystitis glandularis or adenocarcinoma of the urinary bladder in limited specimens, and a proper sampling by transurethral resection of the bladder tumour (TURBT) is essential. In cases where the diagnosis of MC has been made, the optimal treatment cannot be defined due to limited evidence available in literature, but the treatment modality and outcomes are stage dependent and possibly similar to conventional UC.

\section{Nested variant (NV)}

This variant of tumours has been described to mimic benign proliferation of Brunn's nest with bland cytology. In a case series of 23 cases, Cox et al. described key microscopic features including cellular nuclei that lacked significant atypia with the occasional scattered slightly enlarged, hyperchromatic nuclei with small-indistinct nucleoli. The surrounding stroma had a mild-to-moderate fibrous and inflammatory reaction in a majority of cases and a small number exhibited no stromal reaction (42). This variant should be carefully distinguished from an inverted growth pattern of noninvasive urothelial cancer and from von Brunn nests, by the presence of by either muscularis propria invasion, irregularly infiltrating nests of tumour cells, or the presence of a stromal reaction to the tumour (42-45). Using immunohistochemistry, NV demonstrated loss of p27 which is also observed in high grade UC. However, p53, bcl-2 and EGF-r which are markers of adverse behaviour in UC were not observed in NV. In addition, MIB-1 stain may help to distinguish NV from benign urothelial proliferations (46).

In a single institution surgical series, $\mathrm{NV}$ was associated with advanced stage at cystectomy with a 10 -year recurrence free survival (RFS) and CSS of $83 \%$ and $41 \%$ respectively. However, when NV was matched with conventional urothelial cancers, there were no differences noted in survival outcomes (47). In another series of 30 cases, when compared to high grade $\mathrm{UC}, \mathrm{NV}$ was associated with a higher prevalence of muscle invasion at TURBT, extravesical extension at cystectomy and metastatic disease. The response to NAC was also poor (13\%) (48).

Hence, in NV tumours, the key to optimal therapy is accurate histopathological diagnosis so as to be able to effect early radical therapy for best survival outcomes. It is postulated, that late stage clinical presentation in existing literature previously discussed, is contributed, in part, to a delay in appropriate histopathological diagnosis.

\section{Plasmacytoid variant (PV)}

This is a rare variant with less than 200 cases reported in literature so far. At histology, tumour cells are observed to have an eccentrically placed nucleus with abundant eosinophilic cytoplasm reminiscent of plasma cells. The nuclei are of low to intermediate nuclear grade with occasional nuclear pleomorphism (49-52). IHC showed an absence or strongly reduced expression of $\mathrm{E}$ cadherin in PV, a feature associated with advanced pathological stage and nodal metastasis in conventional UC (53).

The natural history of $\mathrm{PV}$ is characterized by advanced stage at presentation and a poor prognosis. In a study comparing $30 \mathrm{PV}$ cases with 278 conventional UC cases, PV patients were more likely to have a higher stage at cystectomy and lymph node metastasis, with positive surgical margins. The median OS and CSS were also dismal at 19 and 22 months respectively. The presence of PV at TURBT was associated with an increased risk of non-organ confined disease compared to conventional UC (OR 4.02, 95\% CI: 10.6-15.22, $\mathrm{P}=0.04)(51)$. In another case series of 31 patients, only half of them presented with non-metastatic disease. Of those with surgically resectable disease, one third received NAC with pathological downstaging seen in the majority of them. Of those who underwent upfront surgery, most of them received adjuvant chemotherapy (54). There is also a clinical predilection for trans-peritoneal spread which may be observed at RC (55), or may occur after curative radical surgery even in those with good pathological response after NAC (54).

Within the AUO-AB05/95 trial of RC with adjuvant cisplatin-based chemotherapy, patients with $\mathrm{PV}$ had poorer OS compared to UC and MPUC (27.4 versus 62.6 and 64.6 months respectively, $\mathrm{P}=0.013$ ) (56).

Therefore, the detection of PV at TURBT should prompt the managing urologist to suspect muscle invasive disease. There is limited evidence for the widespread role of NAC, but where administered there is a high rate of pathological downstaging at RC. Where upfront RC is pursued, there is a high incidence of non-organ confined disease, and hence, a strong consideration should be made for adjuvant cisplatin based chemotherapy. 

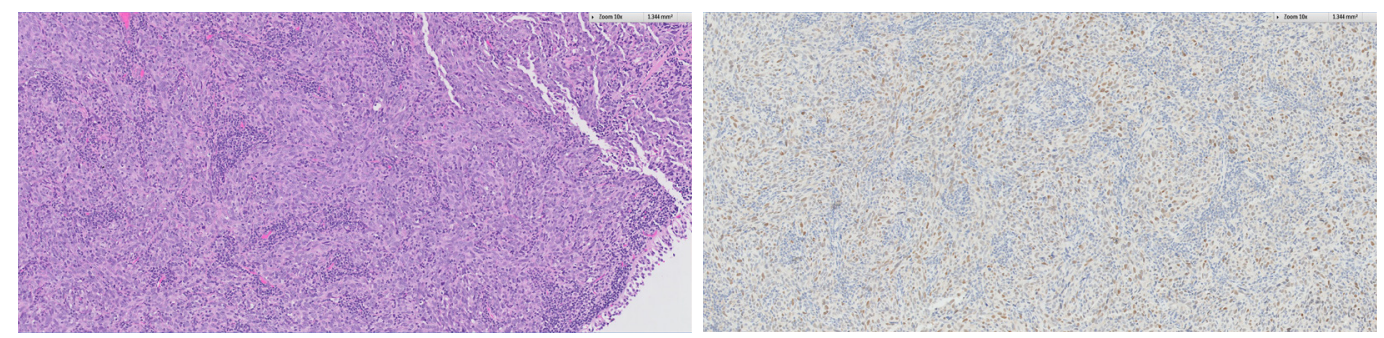

Figure 2 Lymphoepithelioma variant. (A) Haematoxylin and eosin slide showing dense immune cell infiltrates among the tumour cells (larger with prominent nucleus); (B) immunohistochemical staining for p63.

\section{Clear cell variant (CCV) of UC}

This tumour is rare and less than 30 cases have been reported in literature. Tumours with clear cell appearances in the bladder would usually trigger the following differential diagnosis: (I) metastasis from a clear cell renal carcinoma; (II) clear cell adenocarcinoma of the urinary bladder or (III) CCV of a UC. Hence, the accurate histopathological diagnosis would require relevant clinical input to support a possible primary site of cancer, and the application of relevant IHC to exclude clear cell cancers from other possible sources (57-59). The microscopic features of CCV include a clear cell pattern and a glycogenrich cytoplasm. The clear cell pattern may be either focal or extensive in the tumor component (60). Rotellini et al. described a clinical case where a clear cell tumour was found in the urinary bladder of a patient years after a radical nephrectomy for clear cell renal carcinoma. The lesion in the bladder was CK7, CK20 and GATA3 positive. In addition, UroVysion FISH test was also employed which demonstrated aneuploidy of chromosomes 3, 7, 27 and the loss of 9p21 locus in the bladder tumour, which supported its urothelial origin (61).

The clinical outcomes have been variable and not possible to characterize precisely due to the small number of cases reported. The reported outcomes following surgical treatment include mortality from rapid disease progression 9 weeks after RC (58), disease mortality 20 months after RC (59), disease free at 20 months follow-up after TURBT alone (57), and no mortality at 6 months post RC (62) respectively.

Therefore, in CCV, the clinical history of preceding malignancies would aid towards the clinical distinction with other clear cell tumours that may arise within or from without the bladder. This should then be confirmed with a combination of appropriate IHC stains. The natural history of $\mathrm{CCV}$ is not easily characterized with limited data in literature, but there seems to be a propensity towards an aggressive phenotype which should be treated radically where possible.

\section{Lymphoepithelioma variant (LEV)}

The LEV of UC is characterized by syncytial growth pattern of a malignant epithelial component with prominent nuclei and nucleoli, which is densely infiltrated by lymphoid cells predominantly composed of cytotoxic T lymphocytes (63) (Figure 2). These cells may resemble metastatic tumours from the nasopharynx and the strong expression of CK7 would be able to demonstrate a urothelial origin of tumour (64). Other differential diagnosis of malignant lymphomas, undifferentiated UC with lymphocytic infiltrate and small cell carcinoma of the bladder can also be differentiated with the relevant IHC.

LEV has a more favourable long term prognosis especially in cases where the component of conventional high grade $\mathrm{UC}$ is low (65-67), or where the component of LEV is higher (68). In a case series of 34 patients, those with pure LEV treated with bladder TURBT and chemotherapy were disease free at 2 to 5 years follow-up, compared to others with less than $50 \%$ LEV component who had metastatic disease or cancer mortality (67). In cases of LEV where the disease is not muscle invasive, treatment with TURBT and intravesical therapy has been described, and clinical outcomes approximate that of conventional UC $(67,69)$.

Thus, in the management of LEV, the distinction from other lymphoid malignancies is important, and treatment options would mirror that of conventional UC. The natural history of LEV is likely to be similar or better than that of $\mathrm{UC}$ when compared stage for stage.

\section{Lipid rich variant}

The lipid rich variant (LRV) has microscopic features of 


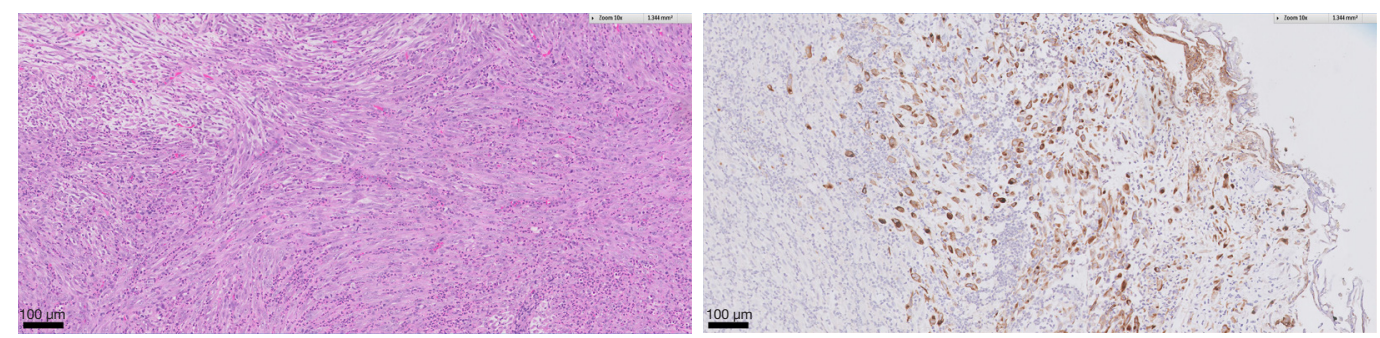

Figure 3 Sarcomatoid carcinoma. (A) Haematoxylin and eosin slide showing a combination of malignant epithelial and mesenchymal cells; (B) immunohistochemical staining for cytokeratin-7 (CK-7).

eccentrically placed nucleus and optically clear cytoplasmic vacuoles resembling lipoblasts or signet-ring cells (7). There is no presence of mucin detectable, which would distinguish it from signet ring cell tumours. The contents of the vacuoles are unknown, although postulated to contain lipids based on animal studies but not demonstrable in human tissue (70). The lipid cell component is variable but can occupy up to $50 \%$ of the tumour, and usually admixed with a component of conventional UC. In the largest case series of 27 cases, other variants were also found with LCV and UC, including MPU (2 cases), PCV (1 case), squamous differentiation ( 2 cases) and concomitant carcinoma-in-situ (8 cases) (71).

The typical presentation is haematuria and the age groups affected range from 42-90 years of age with a male preponderance. The majority of patients present with muscle invasive disease (more than $80 \%$ ) and were treated with RC, including a small proportion (15\%) with adjuvant chemotherapy or chemoradiation therapy. At a median follow-up of 28 months, the OS rate was $30 \%$ in this small cohort. In another case series of 5 patients, a majority of patients had cancer specific mortality between 8 to 76 months from diagnosis, although the modality of treatment was not specified (72).

Hence, in LCV, there is a preponderance to advanced stage at presentation associated with an aggressive behaviour, thereby suggesting that this variant should be treated radically and aggressively upon diagnosis.

\section{Sarcomatoid carcinoma (SC)}

SC is defined as a biphasic tumour consisting of malignant epithelial and mesenchymal elements (73). These tumors are relatively uncommon and most literature is limited to case reports or limited case series (74-78). The microscopic features of SCs include that of biphasic tumours composed of an admixture of carcinomatous and sarcomatous components with an abrupt or gradual transition from one to another (Figure 3). In most cases, the epithelial component consists of high grade UC with possible epidermoid and/or glandular differentiation while the heterologous component consists of chondrosarcoma, malignant fibrous histiocytoma, osteosarcoma, leiomyosarcoma, fibrosarcoma or rhabdomyosarcoma (79). While smoking does not seem to be a risk factor for the development of SC, prior exposure to cyclophosphamide and pelvic irradiation may be risk factors (80). While there is evidence for a monoclonal origin for the development of both the epithelial and mesenchymal components of SC, there may be genetic divergence in the subsequent clonal evolution (81).

As a relatively uncommon variant of urothelial cancers, these patients are rarely recruited into clinical trials and hence, it is challenging to define optimal treatment for these patients. The existing literature supports an aggressive biological behaviour of these tumours, which have a high tendency for muscle invasive disease at clinical presentation (82). $\mathrm{SC}$ was also shown to have a poorer survival compared to conventional urothelial cancers, and a higher $\mathrm{T}$ stage at presentation (82).

In a study of 221 cases with outcomes derived from the SEER database, the disease prognosis was largely dependent on the tumour stage at presentation (79). Individuals with regional or distant metastasis were at a high risk for cancer specific mortality, when compared to those with localized disease. The 1-, 5- and 10-year survival was 53.9\%, 28.4\% and $25.8 \%$ respectively, reflecting the aggressive biological behaviour of SC. There was no significant difference in OS between those treated with TURBT with radical radiation versus RC. However, in light of the aggressive behaviour of SC, one should pursue radical treatment where possible, and RC should be considered where surgically resectable in fit individuals. 


\section{Conclusions}

The tumour variants of UC are detailed based on the WHO 2016 classification of tumors of the urinary system, which highlights the importance of distinct morphological description of histological variants. The treatment and prognosis have been described albeit with a variable level of evidence due to limited cases numbers reported in literature.

Currently, two challenges exist in the clinical management of UC variants in the urinary bladder, namely an accurate histopathological diagnosis and specific treatment strategies. Given that most therapeutic strategies are extrapolated from treatment options of conventional UC, and while applicable in a proportion of patients, there is clearly a need for more defined therapeutics guided by data from specifically designed clinical trials.

\section{Acknowledgments}

Funding: None.

\section{Footnote}

Provenance and Peer Review: This article was commissioned by the Guest Editors (Ja Hyeon Ku, Ho Kyung Seo, Seok Ho Kang) for the series "Muscle-Invasive Bladder Cancer" published in Translational Andrology and Urology. The article has undergone external peer review.

Conflicts of Interest: All authors have completed the ICMJE uniform disclosure form (available at http://dx.doi. org/10.21037/tau.2020.01.02). The series "Muscle-Invasive Bladder Cancer" was commissioned by the editorial office without any funding or sponsorship. The authors have no other conflicts of interest to declare.

Ethical Statement: The authors are accountable for all aspects of the work in ensuring that questions related to the accuracy or integrity of any part of the work are appropriately investigated and resolved.

Open Access Statement: This is an Open Access article distributed in accordance with the Creative Commons Attribution-NonCommercial-NoDerivs 4.0 International License (CC BY-NC-ND 4.0), which permits the noncommercial replication and distribution of the article with the strict proviso that no changes or edits are made and the original work is properly cited (including links to both the formal publication through the relevant DOI and the license). See: https://creativecommons.org/licenses/by-nc-nd/4.0/.

\section{References}

1. Bray F, Ferlay J, Soerjomataram I, Siegel RL, et al. Global cancer statistics 2018: GLOBOCAN estimates of incidence and mortality worldwide for 36 cancers in 185 countries. CA Cancer J Clin 2018;68:394-424.

2. Antoni S, Ferlay J, Soerjomataram I, et al. Bladder Cancer Incidence and Mortality: A Global Overview and Recent Trends. Eur Urol 2017;71:96-108.

3. Flaig TW, Spiess PE, Agarwal N, et al. NCCN Guidelines Insights: Bladder Cancer, Version 5.2018. J Natl Compr Canc Netw 2018;16:1041-53.

4. Chou R, Selph SS, Buckley DI, et al. Treatment of muscleinvasive bladder cancer: A systematic review. Cancer 2016;122:842-51.

5. Veskimäe E, Espinos EL, Kamat AM, et al. What Is the Prognostic and Clinical Importance of Urothelial and Nonurothelial Histological Variants of Bladder Cancer in Predicting Oncological Outcomes in Patients with Muscleinvasive and Metastatic Bladder Cancer? A European Association of Urology Muscle Invasive and Metastatic Bladder Cancer Guidelines Panel Systematic Review. Eur Urol Oncol 2019;2:625-42.

6. Humphrey PA, Moch H, Reuter VE et al. The 2016 WHO Classification of Tumours of the Urinary System and Male Genital Organs_-Part B: Prostate and Bladder Tumours. Eur Urol 2016;70:106-19.

7. Eble JN, Sauter G, Sesterhenn IA, et al. World Health Organization Classification of Tumours. Pathology and Genetics Tumours of the Urinary System and Male Genital Organs 2004;10.

8. Monn MF, Kaimakliotis HZ, Cheng L, et al. Contemporary bladder cancer: Variant histology may be a significant driver of disease. Urol Oncol 2015;33:18.e1518.e20.

9. Xylinas E, Rink M, Brisuda A, et al. Impact of histological variants on oncological outcomes of patients with urothelial carcinoma of the bladder treated with radical cystectomy. Eur J Cancer 2013;49:1889-97.

10. Shah RB, Montgomery JS, Kunju LP, et al. Variant (divergent) histologic differentiation in urothelial carcinoma is under-recognized in community practice: Impact of mandatory central pathology review at a large referral hospital. Urol Oncol 2013;31:1650-5. 
11. Sangoi AR, Beck AH, Hansel DE, et al. Interobserver Reproducibility in the Diagnosis of Invasive Micropapillary Carcinoma of the Urinary Tract Among Urologic Pathologists. Am J Surg Pathol 2010;34:1367-76.

12. Maranchie JK, Bouyounes BT, Wolf WCD, et al. Clinical and pathological characteristics of micropapillary transitional cell carcinoma: A highly aggressive variant. J Urol 2000;163:748-51.

13. Sangoi AR, Higgins JP, McKenney JK, et al. Immunohistochemical comparison of MUC1, CA125, and Her $2 \mathrm{Neu}$ in invasive micropapillary carcinoma of the urinary tract and typical invasive urothelial carcinoma with retraction artifact. Mod Pathol 2009;22:660-7.

14. Willis DL, Fernandez MI, Pisters LL, et al. Clinical Outcomes of cT1 Micropapillary Bladder Cancer. J Urol 2015;193:1129-34.

15. Kamat AM, Gee JR, Dinney CPN, et al. The Case for Early Cystectomy in the Treatment of Nonmuscle Invasive Micropapillary Bladder Carcinoma. J Urol 2006;175:881-5.

16. Amin MB, Ro JY, Silva EG, et al. Micropapillary variant of transitional cell carcinoma of the urinary bladder. Histologic pattern resembling ovarian papillary serous carcinoma. Am J Surg Pathol 1994;18:1224-32.

17. Kwon GY, Ro JY. Micropapillary Variant of Urothelial Carcinoma. Adv Urol 2011;2011:217153.

18. Samaratunga $\mathrm{H}$, Khoo K. Micropapillary variant of urothelial carcinoma of the urinary bladder; a clinicopathological and immunohistochemical study. Histopathology 2004;45:55-64.

19. Kamat AM, Dinney CPN, Tamboli P, et al. Micropapillary bladder cancer. Cancer 2007;110:62-7.

20. Compérat E, Roupret M, Ouzaïd I, et al. Micropapillary urothelial carcinoma of the urinary bladder: a clinicopathological analysis of 72 cases. Pathology 2010;42:650-4.

21. Spaliviero M, Dalbagni G, Al-Ahmadie HA, et al. Clinical Outcome of Patients with T1 Micropapillary Urothelial Carcinoma of the Bladder. J Urol 2014;192:702-7.

22. Sui W, Matulay JT, James MB, et al. Micropapillary Bladder Cancer: Insights from the National Cancer Database. Bladder Cancer 2016;2:415-23.

23. Jackson BL, Mohammed A, Griffiths TRL, et al. Is Immediate Radical Cystectomy Necessary for All Patients with Non-Muscle-Invasive Micropapillary Bladder Cancer? Urol Int 2016;96:32-8.

24. Meeks JJ, Taylor JM, Bochner BH, et al. Pathological response to neoadjuvant chemotherapy for muscle- invasive micropapillary bladder cancer. BJU Int 2013;111:E325-E330.

25. Abufaraj M, Foerster B, Hassler MR, et al. Micropapillary Urothelial Carcinoma of the Bladder: A Systematic Review and Meta-analysis of Disease Characteristics and Treatment Outcomes. Eur Urol 2019;75:649-58.

26. Fernández MI, Williams SB, Parikh S, et al. Clinical risk stratification in patients with surgically resectable micropapillary bladder cancer. BJU Int 2017;119:684-91.

27. Guo CC, Dadhania V, Sykulski M, et al. Gene Expression Profile of the Clinically Aggressive Micropapillary Variant of Bladder Cancer. Eur Urol 2016;70:611-20.

28. Kitazawa M, Kobayashi H, Sekine S, et al. Giant Cell Tumor of the Bladder Associated with Transitional Cell Carcinoma. J Urol 1985;133:472-5.

29. Zhai QJ, Black J, Ro JY, et al. Histologic variants of infiltrating urothelial carcinoma. Arch Pathol Lab Med 2007;131:1244-56.

30. Lopez-Beltran A, Blanca A, Regueiro JC, et al. Pleomorphic giant cell carcinoma of the urinary bladder. Hum Pathol 2009;40:1461-6.

31. Baydar D, Amin MB, Epstein JI. Osteoclast-rich undifferentiated carcinomas of the urinary tract. Mod Pathol 2006;19:161-71.

32. Behzatoğlu K, Durak H, Oznur M, et al. Giant cell tumorlike lesion of the urinary bladder: a report of two cases and literature review; giant cell tumor or undifferentiated carcinoma? Diagn Pathol 2009;4:48.

33. Amir G, Rosenmann E. Osteoclast-like giant cell tumour of the urinary bladder. Histopathology 1990;17:413-8.

34. Clusp BG. Tumors of Urinary Bladder, 3rd Ed. USA: ScienceDirect Topics, 2014:1230.

35. Wu PJ, Su CK, Chen CL. Osteoclast-like Giant Cell Carcinoma of the Urinary Bladder. J Chin Med Assoc 2009;72:495-7.

36. O'Connor RC, Hollowell CM, Laven BA, et al. Recurrent giant cell carcinoma of the bladder. J Urol 2002;167:1784.

37. Alexiev BA, Papadimitriou JC, Drachenberg CB, et al. Polyomavirus (BK)-associated pleomorphic giant cell carcinoma of the urinary bladder: a case report. Pathol Res Pract 2013;209:255-9.

38. Lopez Beltran A, Montironi R, Cheng L. Microcystic urothelial carcinoma: morphology, immunohistochemistry and clinical behaviour. Histopathology 2014;64:872-9.

39. Venyo AKG. Microcystic Variant of Urothelial Carcinoma. Adv Urol 2013;2013:654751.

40. Rugvedita P. P Rugvedita Bladder urothelial carcinomainvasive microcystic variant 2013 Pathol Outlines. 
41. Paz A, Rath-Wolfson L, Mukamel E, et al. The clinical and histological features of transitional cell carcinoma of the bladder with microcysts: analysis of 12 cases. Br J Urol 1997;79:722-5.

42. Cox R, Epstein JI. Large Nested Variant of Urothelial Carcinoma: 23 Cases Mimicking von Brunn Nests and Inverted Growth Pattern of Noninvasive Papillary Urothelial Carcinoma. Am J Surg Pathol 2011;35:1337-42.

43. Murphy WM, Deana DG. The nested variant of transitional cell carcinoma: a neoplasm resembling proliferation of Brunn's nests. Mod Pathol 1992;5:240-3.

44. Holmäng S, Johansson SL. The Nested Variant of Transitional Cell Carcinoma - A Rare Neoplasm with Poor Prognosis. Scand J Urol Nephrol 2001;35:102-5.

45. Drew PA, Furman J, Murphy WM, et al. The nested variant of transitional cell carcinoma: an aggressive neoplasm with innocuous histology. Mod Pathol 1996;9:989-94.

46. Lin O, Cardillo M, Reuter VE, et al. Nested Variant of Urothelial Carcinoma: A Clinicopathologic and Immunohistochemical Study of 12 Cases. Mod Pathol 2003;16:1289-98.

47. Linder BJ, Frank I, Tarrell RF, et al. Outcomes Following Radical Cystectomy for Nested Variant of Urothelial Carcinoma: A Matched Cohort Analysis. J Urol 2013;189:1670-5.

48. Wasco MJ, Daignault S, Shah RB, et al. Nested variant of urothelial carcinoma: a clinicopathologic and immunohistochemical study of 30 pure and mixed cases. Hum Pathol 2010;41:163-71.

49. Lopez-Beltran A, Requena MJ, Cheng L, et al. Plasmacytoid urothelial carcinoma of the bladder. Hum Pathol 2009;40:1023-8.

50. Nigwekar P, Tamboli P, Amin MB, et al. Plasmacytoid Urothelial Carcinoma: Detailed Analysis of Morphology With Clinicopathologic Correlation in 17 Cases. Am J Surg Pathol 2009;33:417-24.

51. Kaimakliotis HZ, Monn MF, Cary KC, et al. Plasmacytoid variant urothelial bladder cancer: Is it time to update the treatment paradigm? Urol Oncol 2014;32:833-8.

52. Ro JY, Shen SS, Cho NH, et al. Plasmacytoid Transitional Cell Carcinoma of Urinary Bladder: A Clinicopathologic Study of 9 Cases. Am J Surg Pathol 2008;32:752-7.

53. Keck B, Stoehr R, Lehmann J, et al. The plasmacytoid carcinoma of the bladder-rare variant of aggressive urothelial carcinoma. Int J Cancer 2011;129:346-54.

54. Dayyani F, Czerniak BA, Dinney CP, et al. Plasmacytoid Urothelial Carcinoma, a Chemosensitive Cancer with
Poor Prognosis, and Peritoneal Carcinomatosis. J Urol 2013;189:1656-61.

55. Ricardo-Gonzalez RR, Nguyen M, McKenney JK, et al. Plasmacytoid Carcinoma of the Bladder: A Urothelial Carcinoma Variant With a Predilection for Intraperitoneal Spread. J Urol 2012;187:852-5.

56. Keck B, Wach S, Stoehr R, et al. Plasmacytoid variant of bladder cancer defines patients with poor prognosis if treated with cystectomy and adjuvant cisplatin-based chemotherapy. BMC Cancer 2013;13:71.

57. Kotliar SN, Wood CG, Oyasu R, et al. Transitional cell carcinoma exhibiting clear cell features. A differential diagnosis for clear cell adenocarcinoma of the urinary tract. Arch Pathol Lab Med 1995;119:79-81.

58. Kramer MW, Abbas M, Pertschy S, et al. Clear-cell variant urothelial carcinoma of the bladder: a case report and review of the literature. Rare Tumors 2012;4:e48.

59. Yamashita R, Yamaguchi R, Tobisu K, et al. Urothelial carcinoma (clear cell variant) diagnosed with useful immunohistochemistry stain. Int J Urol 2006;13:1448-50.

60. Lopez-Beltran A. Further commentary: tumours of the urinary system. In: Eble JN, Epstein JI, Sesterhenn IA. editors. Pathology and Genetics of Tumours of the Urinary System and Male Genital Organs. Lyon: IARC Press, 2004:90-134.

61. Rotellini M, Fondi C, Raspollini MR, et al. Clear Cell Carcinoma of the Bladder in a Patient With a Earlier Clear Cell Renal Cell Carcinoma: A Case Report With Morphologic, Immunohistochemical, and Cytogenetical Analysis. Appl Immunohistochem Mol Morphol 2010;18:396-9.

62. Braslis KG, Jones A, Murphy D. Clear cell transitional cell carcinoma. Aust N Z J Surg 1997;67:906-8.

63. Izquierdo-García FM, Garcia-Diez F, Suarez-Vilela D, et al. Lymphoepithelioma-like carcinoma of the bladder: three cases with clinicopathological and $\mathrm{p} 53$ protein expression study. Virchows Arch 2004;444:420-5.

64. Yoshino T, Ohara S, Moriyama H. Lymphoepitheliomalike carcinoma of the urinary bladder: a case report and review of the literature. BMC Res Notes 2014;7:779.

65. Holmäng S, Borghede G, Johansson SL. Bladder carcinoma with lymphoepithelioma-like differentiation: A report of 9 cases. J Urol 1998;159:779-82.

66. Lopez-Beltrán A, Luque RJ, Quintero A, et al. Lymphoepithelioma-like carcinoma of the urinary bladder: a clinicopathologic study of 13 cases. Virchows Arch 2001;438:552-7.

67. Williamson SR, Zhang S, Tan PH, et al. 
Lymphoepithelioma-like Carcinoma of the Urinary

Bladder: Clinicopathologic, Immunohistochemical, and

Molecular Features. Am J Surg Pathol 2011;35:474-83.

68. Porcaro AB, Gilioli E, Migliorini F, et al. Primary lymphoepithelioma-like carcinoma of the urinary bladder:

Report of one case with review and update of the literature after a pooled analysis of 43 patients. Int Urol Nephrol 2003;35:99.

69. Tamas EF, Nielsen ME, Epstein JI, et al.

Lymphoepithelioma-like carcinoma of the urinary tract: a clinicopathological study of 30 pure and mixed cases. Mod Pathol 2007;20:828-34.

70. Borzacchiello G, Ambrosio V, Roperto F, et al. Rare tumours in domestic animals: a lipid cell variant of urothelial carcinoma of the urinary bladder in a cow and a case of vesical carcinosarcoma in a dog. Vet Res Commun 2004;28 Suppl 1:273-4.

71. Lopez-Beltran A, Amin MB, McKenney JK, et al. Urothelial Carcinoma of the Bladder, Lipid Cell Variant: Clinicopathologic Findings and LOH Analysis. Am J Surg Pathol 2010;34:371-6.

72. Leroy X, Gonzalez S, Aubert S, et al. Lipoid-cell Variant of Urothelial Carcinoma: A Clinicopathologic and Immunohistochemical Study of Five Cases. Am J Surg Pathol 2007;31:770-3.

73. Wick MR, Swanson PE. Carcinosarcomas: current perspectives and an historical review of nosological concepts. Semin Diagn Pathol 1993;10:118-27.

74. Giannopoulos A, Alivizatos G, Dimopoulos MA. Carcinosarcoma of the Bladder. Br J Urol 1991;67:106-7.

Cite this article as: Tiwari RV, Ngo NT, Lee LS. The optimal management of variant histology in muscle invasive bladder cancer. Transl Androl Urol 2020;9(6):2965-2975. doi: 10.21037/ tau.2020.01.02
75. Lopez-Beltran A, Pacelli A, Blute ML, et al. Carcinosarcoma and sarcomatoid carcinoma of the bladder: Clinicopathological study of 41 cases. J Urol 1998;159:1497-503.

76. Cheng L, Zhang S, Harrison BT, et al. Sarcomatoid Carcinoma of the Urinary Bladder: The Final Common Pathway of Urothelial Carcinoma Dedifferentiation. Am J Surg Pathol 2011;35:e34-e46.

77. Hoshi S, Sasaki M, Tukigi M, et al. Case of carcinosarcoma of urinary bladder obtained a pathologically complete response by neoadjuvant chemoradiotherapy. Int J Urol 2007;14:79-81.

78. Ogishima T, Kawachi Y, Tanaka T, et al. Sarcomatoid carcinoma and carcinosarcoma of the urinary bladder. Int J Urol 2002;9:354-8.

79. Wang J, Wang FW, Kessinger A, et al. Clinical features of sarcomatoid carcinoma (carcinosarcoma) of the urinary bladder: analysis of 221 cases. Sarcoma 2010;2010:454792.

80. Lopez-Beltran A, Luque RJ, Montironi R, et al. Changes produced in the urothelium by traditional and newer therapeutic procedures for bladder cancer. J Clin Path 2002;55:641-7.

81. Sung MT, Wang M, Lopez-Beltran A, et al. Histogenesis of sarcomatoid urothelial carcinoma of the urinary bladder: evidence for a common clonal origin with divergent differentiation. J Pathol 2007;211:420-30.

82. Wright JL, Black PC, Dinney CP, et al. Differences in survival among patients with sarcomatoid carcinoma, carcinosarcoma and urothelial carcinoma of the bladder. J Urol 2007;178:2302-6; discussion 2307. 